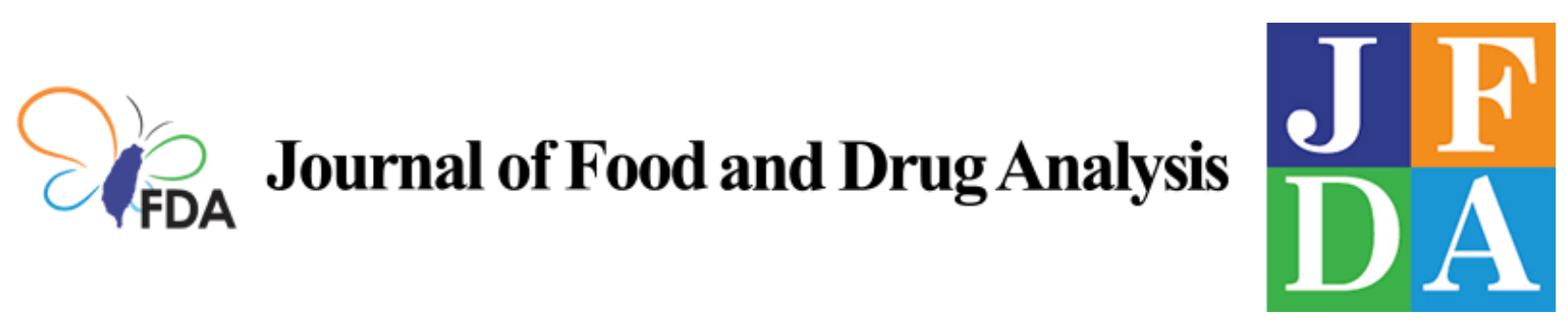

Volume 28 | Issue 3

Article 12

2020

\title{
Corrigendum to "Physicochemical analysis and nonisothermal kinetic study of sertralineelactose binary mixtures"
}

Follow this and additional works at: https://www.jfda-online.com/journal

Part of the Food Science Commons, Medicinal Chemistry and Pharmaceutics Commons, Pharmacology Commons, and the Toxicology Commons

(c) (i) (9)

This work is licensed under a Creative Commons Attribution-Noncommercial-No Derivative Works 4.0 License.

\section{Recommended Citation}

Monajjemzadeh, Farnaz (2020) "Corrigendum to "Physicochemical analysis and nonisothermal kinetic study of sertralineelactose binary mixtures"," Journal of Food and Drug Analysis: Vol. 28 : Iss. 3 , Article 12.

Available at: https://doi.org/10.38212/2224-6614.3170

This Corrigendum is brought to you for free and open access by Journal of Food and Drug Analysis. It has been accepted for inclusion in Journal of Food and Drug Analysis by an authorized editor of Journal of Food and Drug Analysis. 


\section{Corrigendum}

Available online 28 August 2020.

$\mathrm{T}$ his is an announcement to correct the affiliation by adding "a" which is "Food and Drug Safety Research Center, Tabriz University of Medical Sciences, Tabriz, Iran "to the corresponding author of "Farnaz Monajjemzadeh".

\section{Articles:}

1. Corrigendum to "Physicochemical analysis and nonisothermal kinetic study of sertraline-lactose binary mixtures" [J Food Drug Anal 25 (2017) 709-716].

\section{Full Text:}

Physicochemical analysis and nonisothermal kinetic study of sertraline-lactose binary mixtures

Faranak Ghaderi a,b, Mahboob Nemati a,c, Mohammad Reza Siahi-Shadbad c,d, Hadi Valizadeh $^{\mathrm{e}}$, Farnaz Monajjemzadeh ${ }^{\mathrm{a}, \mathrm{d}, \mathrm{c}}$,* a Food and Drug Safety Research Center, Tabriz University of Medical Sciences, Tabriz, Iran

${ }^{b}$ Department of Drug and Food Control, Urmia University of Medical Sciences, Urmia, Iran

${ }^{c}$ Department of Pharmaceutical and Food Control, Tabriz University of Medical Sciences, Tabriz, Iran

d Drug Applied Research Center, Tabriz University of Medical Sciences, Tabriz, Iran

e Department of Pharmaceutics, Tabriz University of Medical Sciences, Tabriz, Iran 